\title{
Pulmonary hypertension could be a risk for deep vein thrombosis in lower extremities after joint replacement surgery
}

\author{
(iD) Paerhati Rexiti ${ }^{1}$ \\ (iD)Minawaer Wutiku² \\ (iD) Wuhuzi Wulamu' \\ (iD) FengZhou Bai \\ (iD) $\mathrm{LiCOO}^{1}$
}

1. Department of Orthopaedics, The First Affiliation Hospital of Xinjiang Medical University, Urumqi, China. 2. Department of Sonography, Fourth Affiliated Hospital of Xinjiang Medical University, Urumqi, China.

\section{SUMMARY}

A background of Pulmonary Hypertension (PH) indicates a progressive elevation of pulmonary vascular resistance, leading to overfilling, elevation of venous pressure, congestion in various organs, and edema in the venous system. This study aimed to investigate whether $\mathrm{PH}$ is a risk factor for deep vein thrombosis (DVT) of the lower extremities after hip and knee replacement surgery.

METHODS: A total of 238 patients who received joint replacement of lower extremities in our department of orthopedics from January 2009 to January 2012 were examined by echocardiography and Color Doppler flow imaging (CDFI) of the lower extremities. Based on pulmonary artery pressure (PAP), the patients were divided into a normal PAP group $(n=214)$ and PH group $(n=24)$. All the patients were re-examined by CDFI during post-operative care.

RESULTS: Among the 238 patients, 18 had DVT in the lower extremities after the operation. DVT total incidence rate was 7.56\% (18/238). In the PH group, 11 patients had DVT (45.83\%, 11/24), but in the normal PAP group, only 7 had DVT (3.27\%, 7/214). The incidence of DVT was significantly lower in the normal PAP group than in the $P H$ group $(P<0.01)$. In addition, there was a positive correlation between PAP and the incidence of DVT.

CONCLUSION: PH could be a high-risk factor for the occurrence of DVT in patient's lower extremities after joint replacement surgeries. KEYWORDS: Hypertension, Pulmonary. Arthroplasty, Replacement. Venous Thrombosis. Risk factors.

\section{INTRODUCTION}

Deep venous thrombosis (DVT) is one of the major complications after joint replacement ${ }^{1}$. DVT affects the patient's postoperative rehabilitation, and it may even lead to fatal pulmonary embolism $(\mathrm{PE})^{2}$. Effective preventive measures could lower the risk of venous thromboembolism (VTE), alleviate pain, and reduce health care costs ${ }^{3}$. The Chinese Orthopedic Association (COA) specially formulated guidelines for the prevention of VTE in major orthopedic surgeries in order to guide clinical thrombosis prevention in orthopedic surgery. However, it remains unclear whether pulmonary hypertension $(\mathrm{PH})$ is a risk factor of DVT. 
In this retrospective study, we enrolled patients who underwent hip and/or joint replacement surgeries in the First Affiliation Hospital of Xinjiang Medical University from January 2009 to January 2012 and examined the correlation of PH with DVT after hip or knee replacement surgeries.

\section{METHODS}

Patients

This study was approved by the Institute of Ethics Committee of the First Affiliation Hospital of Xinjiang Medical University (No. 20130325-01), and all patients signed the consent form. Among all the patients who underwent joint replacement at our orthopedic center from January 2009 to January 2012, 238 received preoperative echocardiography, venous CDFI and postoperative CDFI examinations of the lower extremities. The patients included 89 males and 149 females, aged 54 to 92 (average age 65.9 years). There were 149 cases of total knee replacement surgery in knee joint osteoarthritis, 74 cases of total joint replacement in hip joint osteoarthritis, and 15 cases of hip replacement surgeries after hip fracture (10 total joint replacements, and 5 semi-joint replacements). The 238 patients were divided into two groups: the normal PAP group and $\mathrm{PH}$ group, according to their preoperative pulmonary artery pressure (PAP).

\section{Diagnostic methods}

Normal mean pulmonary artery pressure (mPAP) under quiescent conditions detected by Doppler echocardiography is $20-35 \mathrm{mmHg}$. A mPAP of $36-50 \mathrm{mmHg}$ indicates mild $\mathrm{PH}, 51-80 \mathrm{mmHg}$ indicates moderate $\mathrm{PH}$, and $>81 \mathrm{mmHg}$ is diagnosed as severe $\mathrm{PH}$.

The main diagnostic criteria of lower extremity DVT by Doppler echocardiography are as follows: (1) thrombus in the Lumen of vein, the fact that the form of vascular cavities (especially the anterior and posterior diameter) shows little or no change after the probe is pressurized, which is the most reliable sign for diagnosing DVT; (2) disappearance of normal Lumen of vein and emergence of solid echoes of low or ranging intensity; (3) completely obstructed Lumen of vein, no signals of blood flow detected by color and pulse Doppler at the diseased region. Zero increase of blood flow after pressurization of distal limb indicates that the thrombus is located at the spot under examination or at the distal end ${ }^{4}$.

\section{Statistical analysis}

Data were analyzed using SPSS 17.0 software (SPSS Inc., Chicago, IL, USA). The data were expressed as the mean $\pm \mathrm{SD}$ and the comparison between the two groups was performed using the $\chi^{2}$ test. $\mathrm{A} \mathrm{P}<0.05$ was considered statistically significant.

\section{RESULTS}

Amongst the 238 patients, 214 were in the normal PAP group (84 males, 130 females, average age 65.63 years), and 24 patients were in the PH group (5 males, 19 females, average age 68.3 years). A total of 18 cases of lower extremity DVT occurred in both groups; the total occurrence of DVT was $7.56 \%$ (18/238). There were 11 cases of postoperative DVT in lower extremities in the PH group ( 5 males and 6 females, average age 68.7 years, 7 knee replacements, 3 hip replacements, 1 semi-hip joint replacement after hip fracture), which is equivalent to $45.83 \%(11 / 24)$. There were 7 postoperative DVT cases in the normal PAP group (3 males and 4 females, average age 62.4 years, 4 knee replacements and 3 hip replacements), equivalent to $3.27 \%(7 / 214)$.

Statistical analysis showed that the incidence of DVT in the PH group was significantly higher than that in the normal PAP group $(\chi 2=65.776, P<0.01$, Table 1$)$. According to the mPAP values shown in the echocardiography, the incidence of DVT in the normal, mild, moderate, and severe $\mathrm{PH}$ patients was calculated with the application of the Cochran Armitage trend test. The results showed that the incidence of postoperative DVT was inclined to increase with the elevation of preoperative mPAP in patients $(\chi 2=49.996, \mathrm{P}<0.01$, Table 2).

\section{DISCUSSION}

The current diagnostic standard of $\mathrm{PH}$ is $\mathrm{mPAP}>25 \mathrm{mmHg}$ at sea level and under a quiescent

TABLE 1. COMPARISON OF THE CASES OF POSTOPERATIVE LOWER EXTREMITIES DVT IN TWO GROUPS

\begin{tabular}{l|l|l} 
& $\mathrm{PH}$ (percentage) & Non-PH (percentage) \\
\hline DVT & $11(45.83 \%)$ & $7(3.27 \%)$ \\
\hline Non-DVT & $13(54.17 \%)$ & $207(96.73)$ \\
\hline Total & 24 & 214 \\
\hline
\end{tabular}


TABLE 2. THE RELATIONSHIP BETWEEN MPAP AND THE INCIDENCE OF DVT

\begin{tabular}{l|l|l|l|l|l} 
& & & mPAP $(\mathrm{mmHg})$ & & Total \\
\cline { 2 - 6 } & $\leq 35$ (normal) & $36 \sim 50($ mild PH) & $50 \sim 80($ moderate $P H)$ & $\geq 81($ severe $P H)$ & \\
\hline DVT & 7 & 7 & 3 & 1 & 18 \\
\hline Non-DVT & 207 & 12 & 1 & 0 & 220 \\
\hline Total & 214 & 19 & 4 & 1 & 238 \\
\hline Incidence $\%)$ & 3.27 & 36.84 & 75 & 100 & 7.56 \\
\hline
\end{tabular}

condition". According to "Guidelines for the diagnosis and treatment of pulmonary hypertension" published by the European Respiratory Society and the European Society of Cardiology in $2009^{6}$, PH is classified into five categories: (1) Pulmonary arterial hypertension (PAH); (2) PH due to left heart disease; (3) PH due to lung diseases and/or hypoxia; (4) Chronic thromboembolic PH; and (5) PH with unclear and/or miscellaneous. Among different types of $\mathrm{PH}$, the typical clinical manifestation is the constant elevation of PAP along with the continuous rise of venous pressure of the right ventricular, which would lead to overfilling, elevation of venous pressure, congestion in various organs as well as edema in the systemic venous system, or even right heart failure ${ }^{5,7}$. Meanwhile, hypoxia could be aggravated due to the lack of effective circulating blood in the systemic circulation. Chronic hypoxia could also cause secondary polycythemia, increased blood viscosity, and elevated circulation resistance. Any cause leading to vein injury, stagnant or slow venous blood flow or hypercoagulative state of blood could potentially be a risk factor

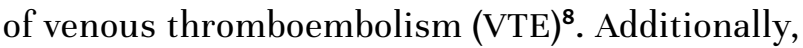
total knee replacement (TKR) or total hip replacement (THR) is a strong stimulating factor for DVT ${ }^{9}$. Therefore, for patients with $\mathrm{PH}$ who also have the aforementioned risk factors for thrombosis, surgeons should be highly sensitive to the incidence of DVT in the perioperative period. A previous report compared patients with PH after THR or TKA and patients without $\mathrm{PH}$ and undergoing these surgeries and found that the preoperative mortality among patients with $\mathrm{PH}$ was 3.7 and 4.6 times higher for those undergoing THA or TKA, respectively ${ }^{10}$.

In 2009, the Chinese Orthopedic Association published a guideline for VTE prevention to guide the clinical practice, which confirmed that major orthopedic surgery is a very high-risk factor of VTE ${ }^{11}$, especially of THR and TKR. The guidelines also summarized other common secondary risk factors including age, trauma, history of VTE, obesity, paralysis, immobility, application of tourniquet in surgery, general anesthesia, malignant neoplasm, central vein catheterization, chronic venous valvular incompetence. However, there is no report on PH as a risk factor of DVT.

During many years of clinical work, we examined clinical data of DVT patients after joint replacement and found abnormalities in the preoperative cardiac echocardiography of most DVT patients. Notably, PAP values increased to different extents, which led us to explore whether postoperative DVT was correlated to the changes in hemodynamics and hypercoagulative state that caused by elevated PAP. In this study, we analyzed the clinical data of 238 patients during three years. By comparing the incidence of postoperative DVT between the normal PAP group and $\mathrm{PH}$ group, we found that patients with $\mathrm{PH}$ had a significantly higher occurrence of DVT in the lower extremities compared with the normal PAP group. We believe that orthopedic surgeons should pay close attention to patients diagnosed with $\mathrm{PH}$ in preoperative echocardiography.

Among different means of clinical examination, right heart catheterization is a golden diagnostic criterion of $\mathrm{PH}^{12}$. However, this cannot be applied as a routine test because of its invasiveness. Doppler echocardiography is the most commonly used non-invasive, convenient, accurate, and reproducible method of examination. Many studies showed that PH diagnosis by echocardiography maintained a good correlation with the measured PAP from the right heart catheter ${ }^{13}$. In this study, we found that the risk of postoperative DVT was likely to increase with the rise of mPAP values in preoperative echocardiography, which indicated the correlation between postoperative DVT and preoperative mPAP value in PH patients. In fact, mPAP value is an exclusive risk factor for $\mathrm{COPD}^{14}$. 
In the intermediate or late stage of heart diseases, the prognosis could be deteriorated if the diseases were accompanied by $\mathrm{PH}^{15}$. Among the 11 postoperative DVT patients in PH group, 4 cases had problems in the left heart function, three of them suffered from aortic valve insufficiency and one suffered from mitral insufficiency. Orthopedic surgeons should pay particular attention to such patients with $\mathrm{PH}$ in the perioperative stage to prevent the occurrence of DVT. In addition, the average age of the 238 patients in this study was relatively high, and the operation procedures were difficult to perform. So preoperative echocardiography could not only assess general heart function but also enable the physician to know the patient's PAP value. Therefore, we believe that echocardiography should be considered as one of the routine tests of preoperative examination.

Currently, the literature reports that postoperative DVT mostly occurs in the vena cava. However, among the 18 postoperative DVT patients, the thrombus appeared in the venous plexus of calf muscles in 4 patients, with 2 patients in each group. There are fewer venous valves in the venous plexus of calf muscles, slow blood flow, absence of hard tissues as deep fascia, and vulnerability of the lumen to dilation, which makes it a likely area of thrombosis. Thrombus in the plexus of calf muscles accounts for $40 \%$ of peripheral deep venous thrombosis in the lower extremities. $20 \%$ of undiscovered thrombus in the plexus of calf muscles develops towards the proximal end in the following two weeks ${ }^{16}$. Among those who died of unknown causes within two weeks after hip and knee replacement, most died from pulmonary embolism caused by shedding of emboli of DVT in lower extremities ${ }^{17,18}$. Therefore, for PH patients with thrombosis in the plexus of calf muscles, surgeons should review the ultrasound test and reinforce follow-up anticoagulation therapy to avoid the development to real DVT or even fatal pulmonary embolism (PE) after discharge from hospital.

\section{CONCLUSION}

PH is a high-risk factor for DVT in the lower extremities post-joint replacement. The pre-existing slow blood flow in the vein and highly coagulative state of patients with $\mathrm{PH}$ are risk factors of thrombosis and likely to persist for a long time after the operation. Patients with PH should be informed of thrombosis prevention after discharge from hospital in order to reduce DVT and mortality rate.

\section{Financial Disclosure}

No financial disclosure was declared.

\section{Conflict of Interest}

No conflict of interest was declared.

\section{Authors Contributions}

Paerhati Rexiti, , Minawaer. Wutiku, ${ }^{\text {\$ }}$, Wuhuzi. Wulamu FengZhou Bai, Li Cao

\$First co-authors who contributed equally.

\section{RESUMO}

OBJETIVO: A hipertensão pulmonar (HP) indica elevação progressiva da resistência vascular pulmonar, levando ao excesso de enchimento, elevação da pressão venosa, congestão em vários órgãos e edema no sistema venoso. Este estudo teve como objetivo investigar se a HP é um fator de risco para trombose venosa profunda (TVP) das extremidades inferiores após cirurgia de prótese de quadril e joelho.

MÉTODOS: Um total de 238 pacientes que receberam a substituição da articulação das extremidades inferiores em nosso departamento de ortopedia de janeiro de 2009 a junho de 2012 foi examinado por ecocardiograma e fluxo de imagem Doppler colorido (CDFI) dos membros inferiores. De acordo com a pressão arterial pulmonar (PAP), os pacientes foram divididos em grupo PAP normal ( $n=214) e$ grupo $\mathrm{PH}(n=24)$. Todos os pacientes foram reexaminados por CDFI durante os cuidados pós-operatórios.

RESULTADOS: Entre os 238 pacientes, 18 pacientes tiveram TVP nas extremidades inferiores após a operação. A taxa de incidência total de TVP foi de 7,56\% (18/238). No grupo PH, 11 pacientes tiveram TVP (45,83\%, 11/24), mas no grupo PAP normal, apenas sete pacientes tiveram TVP (3,27\%, 7/214). A incidência de TVP foi significativamente menor no grupo PAP normal do que no grupo $P H(P<0,01)$. Além disso, houve uma correlação positiva entre a PAP e a incidência de TVP.

CONCLUSÃO: A HP poderia ser um fator de alto risco para a ocorrência de TVP nas extremidades inferiores do paciente após cirurgias de substituição articular.

PALAVRAS-CHAVE: Hipertensão pulmonar. Artroplastia de substituição. Trombose venosa. Fatores de risco. 


\section{REFERENCES}

1. Zhu S, Song Y, Chen X, Qian W. Traditional Chinese and Western medicine for the prevention of deep venous thrombosis after lower extremity orthopedic surgery: a meta-analysis of randomized controlled trials, J Orthop Surg Res. 2018;13(1):79.

2. Johnson R, Green |R, Charnley |. Pulmonary embolism and its prophylaxis following the Charnley total hip replacement. Clin Orthop Relat Res. 1977;(127):123-32.

3. Ollendorf DA, Vera-Llonch M, Oster G. Cost of venous thromboembolism following major orthopedic surgery in hospitalized patients. Am J Health Syst Pharm. 2002;59(18):1750-4.

4. Subramaniam RM, Snyder B, Heath R, Tawse F, Sleigh J. Diagnosis of lower limb deep venous thrombosis in emergency department patients: performance of Hamilton and modified Wells scores. Ann Emerg Med. 2006;48(6):678-85.

5. Barst RJ, McGoon M, Torbicki A, Sitbon O, Krowka M, Olschewski H, et al. Diagnosis and differential assessment of pulmonary arterial hypertension, J Am Coll Cardiol. 2004;43(12 Suppl S):40S-7S.

6. Task Force for Diagnosis and Treatment of Pulmonary Hypertension of European Society of Cardiology (ESC); European Respiratory Society (ERS); International Society of Heart and Lung Transplantation (ISHLT), Galiè N, Hoeper MM, Humbert M, Torbicki A, Vachiery JL, Barbera JA, et al. Guidelines for the diagnosis and treatment of pulmonary hypertension. Eur Respir J. 2009;34(6):1219-63.

7. Galiè N, Ghofrani HA, Torbicki A, Barst RJ, Rubin LJ, Badesch D, et al. Sildenafil citrate therapy for pulmonary arterial hypertension. N Engl ] Med. 2005;353(20):2148-57.

8. Salvati EA, Pellegrini Jr VD, Sharrock NE, Lotke PA, Murray DW, Potter H, et al. Recent advances in venous thromboembolic prophylaxis during and after total hip replacement. J Bone Joint Surg Am. 2000;82(2):252-70.
9. Cardiovascular Disease Educational and Research Trust; Cyprus Cardiovascular Disease Educational and Research Trust; European Venous Forum; International Surgical Thrombosis Forum; International Union of Angiology; Union Internationale de Phlébologie. Prevention and treatment of venous thromboembolism. International Consensus Statement (guidelines according to scientific evidence). Int Angiol. 2006;25(2):101-61.

10. Memtsoudis SG, Ma Y, Chiu YL, Walz JM, Voswinckel R, Mazumdar M. Perioperative mortality in patients with pulmonary hypertension undergoing major joint replacement. Anesth Analg. 2010;111(5):1110-6.

11. Heit JA, O'Fallon WM, Petterson TM, Lohse CM, Silverstein MD, Mohr DN, et al. Relative impact of risk factors for deep vein thrombosis and pulmonary embolism: a population-based study. Arch Intern Med. 2002;162(11):1245-8.

12. van Beek EJ, Brouwerst EM, Song B, Stein PD, Oudkerk M. Clinical validity of a normal pulmonary angiogram in patients with suspected pulmonary embolism: a critical review. Clin Radiol. 2001;56(10):838-42.

13. Chaouat $A$, Naeije R, Weitzenblum E. Pulmonary hypertension in COPD. Eur Respir J. 2008;32(5):1371-85.

14. $\mathrm{Xu} \mathrm{L}, \mathrm{Cai} B \mathrm{BQ}$. Current progress in diagnosis and treatment of pulmonary hypertension in chronic obstructive pulmonary disease. Intern J Respir. 2009;29(6):321-5

15. Chen HZ, Lin GW. Practice of internal medicine. $13^{\text {th }}$ ed. Beijing: The People's Medical Publishing House; 2009.

16. Cogo A, Lensing AW, Prandoni P, Hirsh J. Distribution of thrombosis in patients with symptomatic deep vein thrombosis. Implications for simplifying the diagnostic process with compression ultrasound. Arch Intern Med. 1993;153(24):2777-80.

17. McGrath D, Dennyson WG, Rolland M. Death rate from pulmonary embolism following joint replacement surgery. I R Coll Surg Edinb. 1996;41(4):265-6.

18. Prentice CR. Thromboprophylaxis in elective orthopaedic surgery: what is the purpose? J Bone Joint Surg Br. 1997;79(6):889-90. 